\title{
EXTENT AND DISTRIBUTION OF URBAN TAX DELINQUENCY
}

\author{
FREDERICK L. Bird*
}

The general property tax has developed a degree of unreliability since $193^{\circ}$ which has been particularly disconcerting to municipal governments throughout the United States. But whatever may be said of its imperfections, it continues to be the chief dependence of the local revenue system and, as such, has special need for an appraisal based on recent performance.

The peculiar importance of this major source of municipal revenue may best be determined by consideration of its relation to the budget. It is, in the first place, a deficiency tax. The budget makers, in arriving at the revenue estimate for the year, customarily total the miscellaneous items, usually minor in amount, and then set the general property tax levy at a figure which will fill the broad gap to bring revenues into balance with appropriations. While this procedure is not tenable in those municipalities which operate under a rigid tax rate limitation, it is so generally the practice as to emphasize the necessity for stability and regularity in the inflow of ad valorem tax receipts.

Not only is the general property tax depended upon to provide sixty per cent or more of the annual operating revenue in most municipalities, but in the past it has been. rather universally treated, in the making of budgets, as a thoroughly stable source of income. Revenue estimates ordinarily included the full tax levy for the year, without thought of reserves for possible deficiencies in collection, and depended either on the receipt of delinquent taxes or on temporary borrowing to make up any shortage in the income from the current levy. Uniform budget laws in a few states, in fact, went so far as to make this procedure practically mandatory. Thus the typical budget system, as well as the local revenue system, was geared to the dependability of the general property tax.

What might be called the hand-to-mouth existence of the average city also imposes the requirement of reliability on ad valorem taxes. Very few cities build up large cash reserves for operating purposes. Most of them depend on the current receipts of each year to care for the year's current expenses, and the great majority find it

- A.B., 1913, Lafayette College; M.A., I921, Ph.D., 1931, Columbia University. Director of Municipal Research, Dun and Bradstreet, Inc. Formerly professor of political science, Occidental College; lecturer on government, Columbia University; editor, Municipal Administration Service monographs; financial adviser, National Emergency Council; consultant, Rural Electrification Administration. Author of various books, articles and pamphlets on municipal administration and finance. 
regularly necessary to do temporary borrowing in anticipation of taxes, particularly as fiscal years and tax collection periods are not, as a rule, well synchronized.

With the majority of cities conducting current operations partially on credit there is still further dependence on the regularity of the major source of income. While tax anticipation loans have long been a popular medium for short term investment, recent experience has shown that their availability 'cannot be relied upon in a crisis when the rate of repayment becomes uncertain. And not only is steadiness of primary income a controlling factor in determining the rate and availability of short term credit, but it has come to be a very influential factor in a municipality's ability to sell bonds advantageously. Few items are scanned more carefully by prospective creditors than the record of tax collections.

Scientific methods of control in the execution of the budget, finally, offer comparatively little relief when receipts from taxes fail to measure up to expectations. Because of the preponderance of fixed and quasi-fixed charges there is a relatively small margin in any municipal budget for the underspending of appropriations to meet a sudden shrinkage in income. To principal and interest requirements for debt, often reaching one-third or more of the total budget, there must be added such fixed charges as those for retirement funds. Salary schedules and increments are often fixed by charter or statute and therefore not subject to hasty reduction, and most of the municipal functions performed are of such basic utility to the community as to prevent their drastic curtailment. Certain of them such as welfare, in fact, tend to become more demanding in periods of declining capacity to collect revenue. In some jurisdictions, moreover, cities acting as the collection agencies for school district, county and state taxes are required by law to remit these levies in full each year, irrespective of funds actually received.

Most municipalities, in other words, entered the period of the depression with their ability to maintain operations adequately, to meet their obligations promptly, to sustain their solvency, and to cope with the special demands of unemployment, dependent on revenue and budget systems which presupposed a steady, even flow of general property taxes which would approximate each year's levy.

Even in the middle 1920's tax delinquency in some cities began to show a gradually upward trend, particularly where land and building booms had created an unsubstantial tax base. There was a warning in this movement which might have been noted, had the tax delinquency index received the amount of attention more recently accorded it. Through 1930, however, the increase in delinquency had not become universal and it had not gained sufficient momentum to threaten seriously the balancing of municipal budgets. The median year-end tax delinquency for $15^{\circ}$ cities of over 50,000 population in 1930 was 00.15 per cent, a record still sufficiently close to normal to make its reattainment appear, at the present time, a fairly satisfactory objective of recovery.

The accompanying chart shows the median year-end delinquency for 150 cities 
of over 50,000 population from 1930 through 1935 inclusive. The percentages represent delinquency at the close of each fiscal year on that year's levy only and do not reflect the likewise retarded collections of delinquent taxes. Including, as they do, 79 per cent of all cities in their population classes, they give a reasonably accurate picture of the average experience of the more important cities generally throughout the country.

Trend of TAX Delinedency, I930-1935

Median Year-end Delinquency of 150 Cities Over 50,000 Population

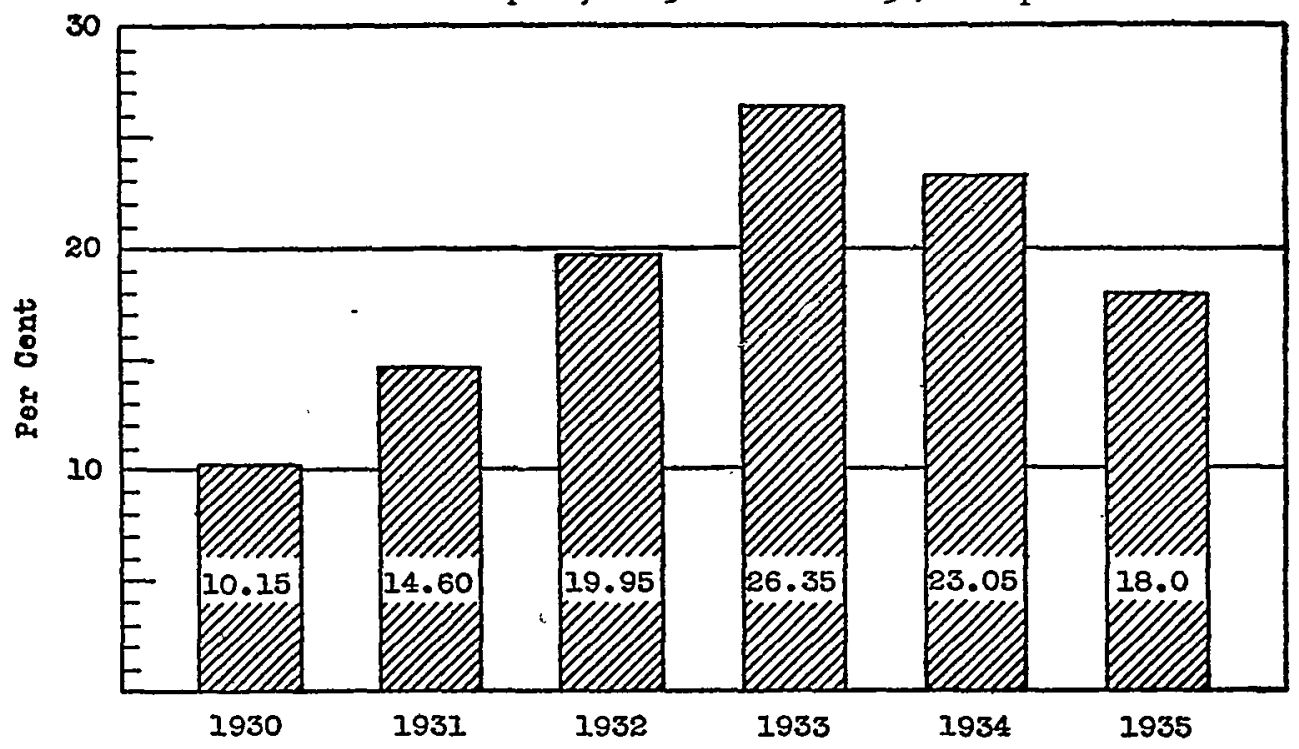

In 1931 the mean delinquency rose 4.45 points to 14.6 per cent, still a fairly comfortable state of affairs from our present point of view. But in 1932 taxpayers stopped paying taxes in earnest and delinquency rose to 9.95 per cent. The following year brought with it its sweeping inundation of bank closings and frozen funds and tax delinquency reached a peak, in 1933, of 26.35 per cent. The average municipality, in other words, had suffered an increase of $x 6.2$. points in delinquency. from $193^{\circ}$ and was able to collect within the year less than three-fourths of the taxes which it had levied that year.

The median figure, needless to say, did not reflect all the realities of the situation. At one extreme were municipalities whose year-end tax delinquency in $1933^{\circ}$ had mounted to thirty, forty, fifty and even as high as sixty per cent. It is not strange that under such circumstances some of them reached the financial breaking point. At the other extreme, a not inconsiderable number of cities continued to enjoy excellent tax collections, some of them showing better results in 1933 than had the average city in 1930 and some experiencing a relatively small increase from normal delinquency. 
Not only was the average city faced with the failure to receive over a fourth of its 1933 taxes when due, but it was confronted with an ominous cessation of delinquent tax receipts which in former years had been depended on to supply the difference. It was the exceptional city that had total tax collections in 1933 reaching $9^{\circ}$ per cent of the year's levy and it was not unusual to find them falling to $7^{\circ}$ per cent or even lower. This predicament posed problems of fiscal administration and policy which have not yet received all the consideration called for, and it encouraged serious concern as to even the ultimate collectibility of large segments of revenue assets which in times past had been confidently depended on. Tax collection administration, budget making and the municipal revenue system lay open to more critical analysis in the light of the weaknesses exposed.

Belying the forebodings of the forecasters of disaster for municipal governments generally, tax collections in 934 took a turn for the better, with a medium improvement of 3.3 points from the peak of 1933 to a year-end delinquency level of 23.05 per cent. While this very modest degree of improvement fell short of reducing the general average even to the 1932 level, it was somewhat reassuring because it was participated in by 83 per cent of the 150 cities. A further cause for encouragement was the influx of back taxes, but this was partially discounted as a dependable index because of the more than $\$ 100,000,000$ advanced for this purpose by the Home Owners' Loan Corporation.

The continued decline in tax delinquency in 1935 was somewhat more conclusive as the median year-end ratio dropped 5.05 points to 18 per cent, indicating that half the ground lost since $193^{\circ}$ had been regained. Here again, however, the degree of recovery was so varied as to call for speculation regarding the causes. While some of the gains by individual cities were still negligible and a few continued to lose ground, 26 of the 150 collected a higher percentage of the year's taxes in 1935 than they did in 1930 and nine others came within a very small margin of equalling their I930 records. The list includes both New York and Philadelphia.

In only a very few of this distinguished group can the results be attributed to a taxpaying capacity. superior to that of 1930 or to drastically lower tax levies. For most of them changes in tax collection procedure have been either a contributing or dominating influence. These changes included the institution of quarterly tax payments, the billing of taxes earlier in the fiscal year, the elimination of personal property taxes in the instance of New York, the advancement of delinquency dates and increase of penalties, the holding of more regular tax sales, and the provision of an instalment system and the remission of penalties on back taxes, contingent upon the prompt payment of current taxes. A more pertinent demonstration would hardly be needed that a goodly portion of the unreliability in general property tax revenue has been the result of faulty administration rather than incapacity to pay.

Somewhat counteracting the fear that the depression would leave many municipalities crippled by the permanent loss of large amounts of revenue anticipated in 
their tax levies has been the continuation of the influx of back taxes which began in 1934. By the close of 1933 many cities found themselves with uncollected taxes approximating or even exceeding an entire year's levy. It is the liberating of these frozen assets which is expediting municipal financial recovery to a degree not reflected in the slow return toward normal of tax collections within the year of levy.

The average city, in 1935, had the novel experience of collecting a slightly larger amount of taxes than called for in the current levy. In III cities of over 50,000 population the median ratio of total collections to the year's levy was ror per cent. In only ig did total collections fall below 95 per cent and at the other extreme they rose to such levels as 122.9 per cent in Seattle and rog.6 per cent in Philadelphia. Except in a minority of instances in which delinquent taxes were pledged as security for debt, the effect was to simplify the balancing of 1935 budgets and to facilitate balanced operations in 1936 .

A preliminary sampling of the tax collection trend in 1936 , based on 50 representative cities, shows current collections averaging 4.I points better than in 1935 and suggests a probable decline in year-end delinquency to the level of $x 93$ r.

Still further refuting the fear that the deflationary influences of the depression would necessitate the ultimate writing off, as unrealizable, of large amounts of levied taxes is the record of recent delinquency on the tax levies of the last four years. It appears that when tax collection administration is organized with even a moderate degree of effectiveness the losses on realty taxes, under average conditions, will be very small. - This does not always apply to personal property taxes, but their relative proportion of the total is sufficiently small, as a rule, to have but a minor effect on total results. In the case of taxes based an speculatively valued unimproved property some losses may be anticipated, but on the whole the collection of delinquent taxes is producing an encouraging record. This is illustrated by the following table showing the median delinquency for 97 cities over 50,000 population, on the levies of the last four years as it stood at the close of the 1935 fiscal year. Data illustrating both the average and the extremes are included.

\section{Delinguency on Recent Levies at End of i935 Fiscal Year}

\begin{tabular}{|c|c|c|c|c|}
\hline Levy of & 1935 & 1934 & 1933 & 1932 \\
\hline Median, 97 Cities & $17.3 \%$ & $10.5 \%$ & $7.0 \%$ & $4 \cdot 4 \%$ \\
\hline Charlotte, N. C. . . . . . . . . . . . . & I9.8 & 12.1 & $9 \cdot 3$ & 6.5 \\
\hline Chattanooga, Tenn. ................ & I6.7 & 7.6 & 6.8 & 3.5 \\
\hline Newark, N. J. ................... & 26.5 & II. 8 & 6.3 & $5 . x$ \\
\hline Yonkers, N. Y. . . . . . . . . . . . . . . & 25.1 & 12.8 & 6.5 & 4.6 \\
\hline Richmond, Va. .................. & 13.4 & $5 \cdot 7$ & 3.3 & I.6 \\
\hline Bridgeport, Conn. .. ............... & II.O & 6.5 & 3.2 & I.3 \\
\hline Flint, Mich. .... & 28.4 & 20.5 & 20.7 & 15.5 \\
\hline Tacoma, Wash. ............... & 29.7 & 19.2 & 21.8 & I0.3 \\
\hline Tampa, Fla. ................. & $3^{8.5}$ & 24.2 & 20.6 & I5.I \\
\hline
\end{tabular}


Discussion thus far has concerned itself primarily with the general trend of municipal tax delinquency. Fully as significant is the relative experience of various types of cities in different sections of the country. The drawing of conclusions and the making of comparisons from the year-end delinquency records of individual cities is somewhat hazardous because of their wide diversity in tax collection practice. Since tax delinquency is as much an index of administrative efficiency as it is of taxpaying capacity, there is always the question as to what part of a given delinquency ratio represents inability to pay and what part official negligence regarding collection. A high end-of-year delinquency may, for example, be mitigated by an excellent record of total collections of delinquent taxes within a short period. Both Massachusetts and New Jersey municipalities, for example, have high year-end delinquency records. In the case of the former, however, it is the result of very late billing and penalty dates, with this shortcoming largely offset by the holding of regular tax sales within a few months of the close of the fiscal year. In the case of the latter, it has been a product of lax traditions of administration, and tax sales often have been perfunctory or even neglected.

Year-end statistics, however, are still of real value in showing comparatively the swing from normal in ability to collect taxes under adverse conditions and in reflecting the degree of synchronization between the fiscal year and the recespt of the year's current taxes. 'The accompanying table shows the year-end delinquency record from I930 through 1935 of 45 representative cities, selected to illustrate four typical conditions: (I) outstandingly good records both as to promptness and stability; (2) records of normally less satisfactory year-end results but relatively good year-to-year stability; (3) records following closely the general average of stability; (4) records indicating an abnormal degree of instability.

Two characteristics in particular explain the remarkably strong records of the cities in Group I. They have unusually well rounded, ample and stable resources and, with possibly one or two exceptions, their methods of tax collection are sound and aggressive.

The cities of Group II likewise have the advantage of resources of better than average stability. Hartford, for example, is a great insurance center as well as the state capital, while in Bayonne well entrenched industries pay over half the taxes. Tax collection administration, however, varies as to effectiveness, with considerable laxity of method in Bayonne, Charleston and Jacksonville and with effective pressure delayed to the second year in the Massachusetts cities.

No such generalization is possible for the rather normal delinquency trend of the cities in Group III. None suffered more than the average from the depression, but the majority was somewhat lacking in effective collection methods. Glendale and New Britain, with more than average efficiency of administration, did better than might have been anticipated, while New York City restored its collections to the I930 level in I935 largely through tax and administrative reforms. 
The Trend of Tax Delineuency, I930-1935

Forty-five Representative Cities over 50,000 Population

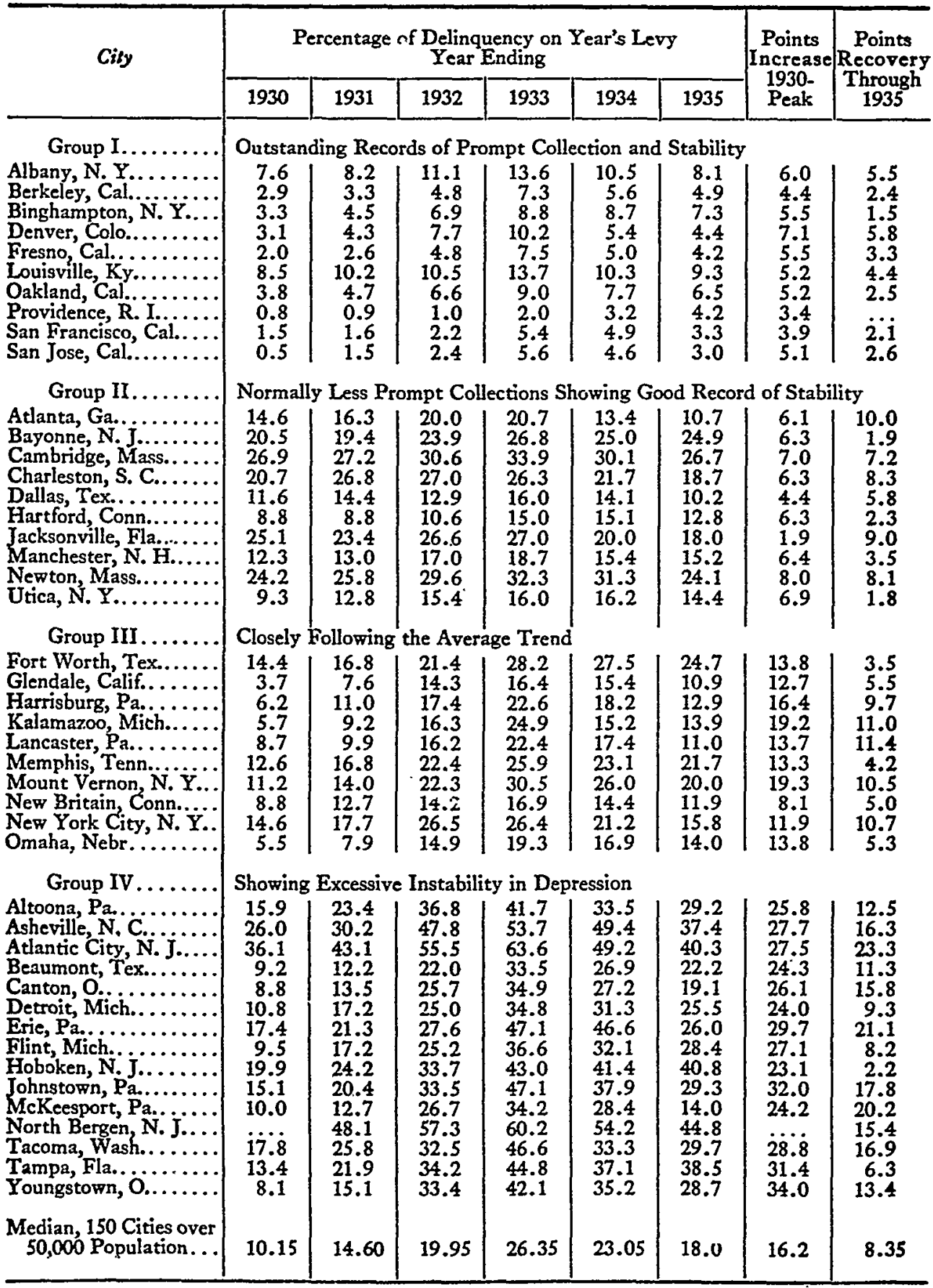


The cities of Group IV readily identify themselves in the classification of those upon which the ravages of the depression fell the most severely. Two-thirds of them, moreover, were forced to default on debt. They include cities dependent upon a single dominant industry-notably automotive, rubber, steel, building material, railroad shops, recreation; cities which were victims of excessive real estate promotion; and cities which experienced the most severe banking disorders. Another characteristic stands out strongly, however. Not one of the fifteen had an outstandingly satisfactory system of tax collection administration and those of the majority were notably mediocre or weak.

Accumulated delinquency needs to be studied in conjunction with the year-end trend to determine the effect of the depression on municipal tax collections. The relation of the total accumulation of delinquent taxes at the close of 1935 to the levy of that year offers opportunity for significant comparisons. Data for ro8 cities of over 50,000 population show the median figure for the entire group to have been 48.4 per cent, indicating that the average municipality was slightly less than one-half year's levy short of realizing the total taxes due at the close of the last fiscal year. As in the case of year-end delinquency, a small group of cities was particularly outstanding for ability to collect taxes. Thirteen of the ro8. showed an accumulated delinquency ratio of less than 25 per cent. Binghamton, N. Y., Providence, San Francisco and Cedar Rapids, Iowa, had ratios below io per cent. At the other extreme, II cities had accumulated tax arrears at the close of 1935 in excess of the year's levy.

Again generalization is complicated by variations in administration as well as in taxpaying capacity. The cities of California, by and large, secured the best results, with most of those of New England, New York, Maryland, and the middle western farm states showing better than average records. The municipalities of Florida, Michigan, Ohio, New Jersey, Washington and South Carolina, on the other hand, had, in general, the poorest records. Throughout the country, however, there is a strong correlation between the rate of delinquency and the combined factors of stability of resources and methods of administration.

The effect of tax delinquency during the depression on the balancing of budgets has been by no means uniformly in proportion to ability to collect taxes. True, those cities which have enjoyed high and prompt collections have had a relatively simple problem of budget balancing, as even the perfunctory policy of depending on the receipt of tax arrears to offset current delinquency at no time left them far short of the cash needed to cover appropriations.

The budgetary experience of cities whose delinquencies approached the average or ran higher, however, was closely related to the effectiveness of the method employed in estimating receipts. Cities which computed estimated receipts, both of current and delinquent taxes, on the basis of actual experience and reasonable expectations were able to hold their operations near enough to a balanced basis to 
avoid financial difficulties even in the most unproductive years. This was done successfully by a few cities whose year-end delinquency ran as high as 35 per cent. The situation did create a serious dilemma, however, for the maintenance of cash basis operations necessitated inflation of the tax levy and the imposition of. a more than normal burden on the actual taxpayers to offset the failure of the delinquents.

A great many cities, particularly in the eastern states, however, made no recognition in their receipt estimates of the trend of tax delinquency. By 1932, as a consequence, they had piled up large cash deficits and by the close of 1933 were confronted by an almost unmanageable state of affairs. In many instances banks had continued to permit the piling up of operating loans and thus had encouraged the maintenance of lax policies. In areas where tax sales were continued regularly and budgets contained reserves sufficient to offset taxes ultimately uncollectible, short term credit usually was still extended when banks had facilities to do so. But where normally lax tax collection administration became more undependable, cities frequently found themselves with their means of financing suddenly terminated. In some instances this precipitated default and, in many others, necessitated the working out of elaborate plans of deficit funding. New York City, for example, had an operating debt of a quarter of a billion dollars at the close of 1933 and was forced to enter into an agreement with the bankers which was.little short of a temporary receivership.

The great majority of such cities have now succeeded, by one means or another, in stabilizing their current accounts, although some will still be engaged, twenty, thirty and even forty years from now, in paying off the bonds floated to finance their operating deficits of the depression. The fact remains, however, that many cities have not improved their budget making policies to guard against the future recurrence of this type of predicament, and many have not altered their methods of tax collection administration to assure themselves of steadier revenues and of sounder credit for emergency borrowing should it become necessary.

The rise of urban tax delinquency has been discussed factually as one of the disturbing phenomena of the depression and the general economic and administrative causes have been pointed out. Brief consideration of the types of property which contributed most to abnormal delinquency, however, will throw further light on possible means of securing greater stability for the major source of municipal income. The evidence points to real estate speculation and the inadequate municipal control of subdivisions as generally responsible for the worst elements of tax delinquency. An intensive survey of urban tax delinquency in 62 cities conducted by the Bureau of the Census, Division of Real Estate Taxation, in $1934,{ }^{1}$ educed the facts that the median rate of delinquency among ten types of property was highest for vacant lots, second and third highest for apartment houses and multiple dwellings and fourth highest for hotels.

${ }^{2}$ U. S. Bureau of the Census, Realty Tax Deunnquency (1934). 
The most thorough extensive analysis of types of tax delinquency which has been made was that of Westchester County, New York, by the staff of the Institute of Public Administration under the auspices of the Westchester County Commission on Government. ${ }^{2}$ This survey covered four cities and 18 towns in a well-to-do section of the New York metropolitan area which experienced very marked growth and speculative real estate activity in the rg2o's. Of 63,494 properties found to be in arrears on 1933 taxes, 50,52I consisted of lots in subdivisions and of parcels of acreage which contained no buildings or other structures. Of the $x 8, x 74$ of these parcels of vacant land whose records were checked back over a period of years, one-fifth were found to have been in arrears continuously since r925. The survey observes, further, that the arrears on homes would not have been sufficiently large to account for the acute crisis in local finance which existed at the end of 1933. The analysis demonstrated with preciseness "the fact that the greater. part of the outstanding arrears of taxes have accumulated in all parts of the county against two types of propertyvacant lands in premature subdivisions, and large multifamily and business buildings erected in premature apartment house and building zones." While similarly complete quantitative analyses have not been made generally, the preponderance of evidence is that the collapse of speculative real estate undertakings has been responsible for a very large share of all abnormally high tax delinquency.

For most cities, the crisis caused by the rapid decline of receipts from general property taxes has passed. Even without a return, as yet, to normal year-end collections, the average city is now in a position to balance its budgets readily through the compensating influx of taxes in arrears. While the stringency was of relatively short duration, it not only worked havoc with the credit and the operating stability and efficiency of a large number of municipalities but left some of them in a position to suffer from its adverse effects for a generation. There could have been no stronger type of demonstration of the need for all the stability possible in the major source of municipal revenue.

A rise in tax arrears is to be anticipated in any major depression, but abnormal increases can be largely guarded against, and unavoidable fluctuations offset by financial planning. Any program looking toward future stability, however, must embody provisions for synchronizing tax and fiscal years, for developing sound, businesslike methods of tax assessing and collecting administration, and for intelligent subdivision control which will discourage the excesses of real estate speculation. Such a program calls, also, for the elimination of perfunctory and visionary revenue estimates in the budget and the adoption of a more realistic basis for this important aspect of budget making.

s Westchester County Commission on Government, Land Use and Local Finance (19.35). 